\title{
INTEGRATED DECISION SUPPORT AND EXPERT SYSTEMS IN A COMPUTER INTEGRATED MANUFACTURING ENVIRONMENT
}

\author{
Chia-hao Chang \\ Dept. of Industrlal \& Systems Eng. \\ University of Michigan-Dearborn \\ Dearborn, Michigan
}

\author{
Jimming T. Lin \\ Faculty of Administration \\ University of Ottawa \\ Ottawa, Ontarlo
}

\begin{abstract}
In a computer integrated manufacturing (CIM) environment, well planning, control and operational process require both expert knowledge of the area, and powerful decision support capabilities. This paper discusses the features of decision support systems and expert systems, and their integration to support the major functions from marketing and strategic level considerations to manufacturing operational planning and process. From the hierarchical structure of information flow in a company, this paper attempts to find the best way of combining decision support systems with expert systems in enhancing the planning. control and operational functions in a CIM environment.
\end{abstract}

\section{INTRODUCTION}

Application of Information Technology has proven significantly improve the productivities in the manufacturing environment. More and more manufacturing functions are computerized, and results are usually encouraging. Among them we can think of CAD (computer-aided design), CAM (computer-aided manufacturing), CAPP (computer-aided process planning), CAT (computer-aided testing), etc.. Then CIM (computer integrated manufacturing), an evolved concept, represents an integration of all the relevant activities. In fact, not only engineering functions are involved, the recent development believes business functions like marketing, sales, distributions, finance and administration are also relevant to the manufacturing production and planning processes. IBM's COPICS (Communication Oriented Production Information and Control System) and MAPIC II (Manufacturing Accounting and Production Information Control System version 2) integrate information across functional areas and manage the resources of manpower, facilities and materials effectively (see [7]). The manufacturing production functions use business data to expedite planning, forecasting, scheduling and control. The trend is to develop a fully integrated system.

\section{APPLICATION OF INFORMATION IECHNOLOGY IN CIM}

\section{Decision Suppont Systems}

Manufacturing planning and control functions were handled manually until the late sixties. Practitioners finally accepted information technology in the manufacturing environment. IBM brought out an integrated concept called COPICS (Communication Oriented Production Information and Control System), which significantly influenced the further development of computer-based production planning and control systems. One group of the early products was referred to as Material Requirements Planning Systems (MRP) which generated material requirements for the manufacturing production lines. Although many successful cases were brought forth, a rather large portion of the attempts to use MRP ended in dissatisfaction and sometimes even failures.

After years of experience, the major causes to MRP's failure were gradually found and corrected. First of all, provided every information known, MRP could mechanically calculate material requirements very precisely, but unfortunately most manufacturing environments were constantly undergoing dynamic changes. Secondly, it would not be realistic to develop production and requirement planning without the awareness of support from manufacturing resources. That included manpower, machinery, material and capital requirements. Realizing the drawback, the new version of MRP with more decison support routines was developed under a new name called manufacturing resource planning (MRP II). Compared to MRP, MRP II puts more emphasis on matching resources with demands in order to attain the corporative plans, that which will eventually be converted to production 
plans. The process is often a recursive one. Attempts and adjustments are required to ensure the feasibility of the outcomes. Potential capacity problems will be identified. The long term capacity planning pinpoints the discrepancy between the demands and the available resources in the long run, and decides on what kind of adjustment is needed to support a realistic master production scheduling.

Getting to the operational level, short term time phased production scheduling is set to observe the predicted loads, job-shop status and bottlenecks. The short term capacity planning will handle the adjustments by temporarily increasing or decreasing its capacities. With those modifications, MRP || becomes more flexible in handling the dynamic environment and the output scheduling is also more realistic (see [5]).

\section{MRP II and likewise systems support} manufacturing management with necessary information so that the planners can make judgment and decisions. Let's use the long term capacity planning as an example. This function needs input knowledge such as the forecast of demands, the current capacity status, the inventory status and the production status. The forecast of demands and master production schedules generated by the systems will indicate a rough estimated manpower and machine capacity in each level of the assembly process. A long term (rough-cut) time-phased capacity requirement will be generated and compared against the existing capacity status. If a manufacturing firm is found undercapacity, the finding may justify the needs for increasing man and machine power. Alternatives such as hiring new workers, increasing work shifts, opening new production lines, installing new machines, replacing current facilities and equipments with more efficient ones, and even building a new plant would be considered possible solutions. On the other hand, when the firm is found constantly overcapacity, solutions like reducing working shitts, laying off employees, closing down production lines and plants will be under consideration to correct the problem. Decision support systems will be used to test alternatives in either case. The objective is to develop a realistic and optimum long term capacity plan. The help from the information models often sharpens up such planning and control functions and improves the overall competitive status.

\section{Expert Systems}

Although the information technology is getting more powerful and sophisticated than ever, in many situations human intelligence and expertise still play a determinant role. Often users' limited knowledge in their areas of responsibility would affect their level of performance. In recent years, the development of knowledge based expert systems provides a solution to permit an expert's periormance to the ordinary users. Although the commercialization of expert systems began only a few years ago, the progress in developing applications for business and industry has been dramatic. Manufacturing systems, by no exception, also find the invaluable use of expert systems to support their operations and management. For example, it is no news for manufacturing engineers and operators to face substantial production line shut down caused by the failure of complex equipments, or spend costly process planning for each new manufacturing part, or go through time consuming scheduling at planning and shop floor levels. All these activities need the knowledge and expertise to perform their corresponding functions. The development of expert systems gives a lot of hope in those areas.

To construct a knowledge based expert system, human expertise is transferred into means that can be accessed by the system, and forms a knowledge base. Knowledge and expertise often need refinement judged by the testing process, and should constantly be updated. The process will continue to keep the system's pertormance at the expert level. Inference mechanism of the system accesses the knowledge base to generate analysis and judgment. User-friendly interface allows non-technical users to operate the system without extensive training. Some system provides explanations behind the generated output when questioned by the user, or suggests alternatives from which the user can choose. For more practical use, some expert systems are constructed so as to make judgment from incomplete or fuzzy information. Although it is costly and time-consuming to build an expert system, there are a lot of attractive benefits. The duplication cost is very low and easy. The systems are highly mobile, eliminating geographical barriers and are available twenty-four hours a day. Besides, the system can incorporate knowledge from different experts from different time and locations into a common knowledge base. However, expert systems do have limitations. For one, they are usually designed to serve specific problems only. They are not the general problem solver, and it is too costly to be one. Because of that reason, only the specific complex problems are considered the targets of expert systems. Process planning, for example, is a major application of expert systems in the manufacturing environment. The function converts the design information into manufacturing process information in terms of process routes, process equipments and tools, 


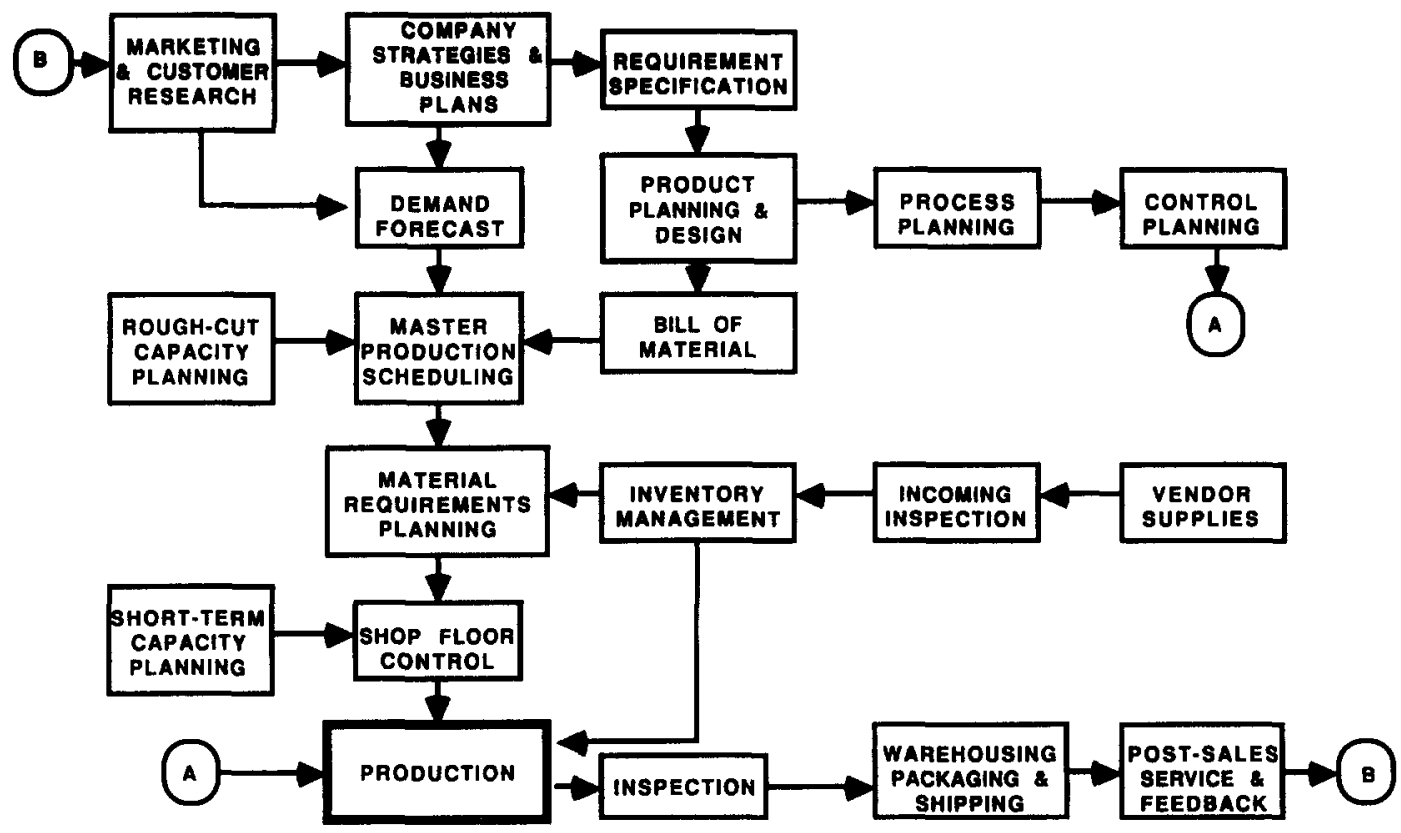

Figure 1. Information flow in a CIM environment

operation sequences, etc., and is considered to be the key element in integrating the computer-aided design (CAD) and the computer-aided manufacturing (CAM). The function requires a considerable amount of expertise, has been the area of expert system application ever since the early eighties. The maintenance of complex equipment is another example. It usually involves fault diagnostic procedures incorporating various maintenance rules and judgment decisions. The personnel expertise and knowledge play an important role in locating the problem and determining the appropriate corrective actions (see [1] and [8]).

\section{INTECRATION OE DECISION SUPPORT AND EXPERT SYSTEMS}

\section{DSS verses ES}

Decision support system provides the flexibility and adaptability in dealing with ill-defined problems, partial information, conflicting objectives and ad hoc questions. Such a system is found particularly useful to support the solutions of a wide range of semistructured and unstructured problems like strategic and tactic planning. Knowledge-based expert system incorporates knowledge from experts to provide users with expert level considerations. Most expert systems are developed to support specific and narrow application domains. DSS and ES represent two kinds of information technology tools serving for distinct purposes, yet they are not necessarily conflicting to each other. In most situations, they can actually complement each other. A combination of DSS and ES can yield an even better result. User may use DSS regarding information acquisition and information evaluation, and at the same time use ES to get intelligence for a particular domain and a suggestion for the tentative decision. The joint effort can provide users with better information to make final decisions.

\section{Information Flow in a ClM Environment}

To determine which kind of information technology, DSS or ES, should be applied to which function in a CIM environment, or whether the integration of DSS and ES would be appropriate for a particular function, one should first study the information flow in the CIM. Most companies now believe the importance of "the voice of customer", and it is the customer requirements that drive the company's operations. The product life cycle in such companies will start with marketing research, where customer needs and competitors' strategies are studied. Collected information will help to set up long term strategies and develop business plans. That is a typical area where traditional decision support systems demonstrate their abilities using modeling, "what-if" simulation, and quantitative analysis to help user reason and make decisions. The marketing research and business plans determine the kinds of product the company wants to produce. The specific descriptions of the product rely on the design and manufacturing considerations. It used to be an iterative process between the product design division and manufacturing division to ensure that the final design meets customer requirements and will not cause manufacturing 
complications. The recent simultaneous engineering concept encourages both design and manufacturing divisions participate in the design process and work together, so the design will be manufacturable and also fully functional in the way customers expect. The final design will be converted to manufacturing process plans by the process planning function. This function requires a lot of knowledge about the manufacturing environment and expertise to develop the route plans. Numerous existing expert systems are able to perform this function. Then the process control plans will be developed to ensure the quality during operation.

On the other hand, the forecast of product demands and the information of available capacities and resources are used to generate manufacturing planning schemes. The master production schedules (MPS) lay out a time-phased product demand, and the material requirements planning (MRP) determines the requirements for each level of a product's structure (bill-of-material). At shop floor, the foremen will adjust the production schedule based on the short term available capacities, resources and production orders. Operations at the production lines usually emphasize on efficiency, productivity and high quality. Various expert systems were developed to support the individual operation (see [2] and [3]).

\section{Intearation of DSS and ES}

Following the flow of information in a CIM environment, we may classify the major functions into three levels: long term strategic planning, short term process and operational planning, and production operations. Marketing and customer research, setting company strategies and business plans all belong to the first category. Traditional decision support systems are developed to support such functions. But expert systems can further play the role of consultants by providing expert advice on complex issues that deal with legal problems, tax problems and others. In that case, outputs from expert systems will be directed to the DSS for possible solutions. DSS here is still the main tool for the user, and ES only plays the supporting role (see [12] and [13]).

From the development of company strategies and business plans to the production stage, MPS, MRP, capacity planning and shop floor control follow one information flow path that is served by MRP (or MRP II) systems. Product design, process and control planning follow the other information flow path, where numerous expert systems have been developed to support these individual functions. The integration of DSS and ES at this level will keep all the current systems with additional components to enhance the overall result. Along the first information flow path, expert knowledge about the customer behavior and forecasting is required to develop viable master production schedules. To choose a capacity adjustment strategy, an expert's advice will make a significant difference. Most shop floor control requires knowledge of manufacturing and plant operation procedures. Therefore expert systems should be developed to assist DSSs in those aforementioned functions. Along the second information flow path, there are expert systems already developed to support product design function and process planning. The results of quantitative analysis provided by DSSs are often used as input to those expert systems. For example, engineering analysis is required during a design process, and DSSs can be useful in choosing a combination of feeding rate and operation speed, and also other parameters in developing process plans. Under that situation, DSS outputs will be directed to the ES (see [4]).

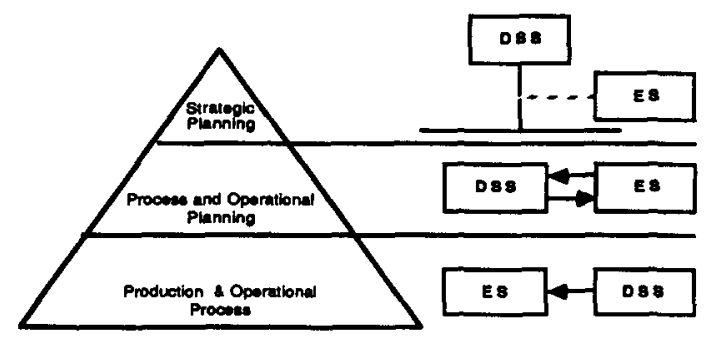

\section{Figure 2. Integration of DSS \& ES In an organization}

At the operational level, many production and operational processes can be benefited by using expert systems achieve expert performance. Most operations at this level require little decision making. For specific operations at a narrow application domain, expert system is the ideal tool. Operations such as welding, material handling, and machining are all becoming the service targets for expert systems (see [11]). Hence it would make a lot of sense to adopt an integrated system if other information systems, when combined with expert systems, would generate more economic and efficient results. Therefore we should use expert systems to perform the operation and use DSS and other information technologies as supplements in the system.

\section{CONCLUSION}

Decision support systems provide the flexibility and adaptability to support the solution of a wide range of semistructured and unstructured problems like strategic and long 
term planning. Expert systems incorporate knowledge from experts to provide users with expert level considerations in specific and narrow application domains. In a computer integrated manufacturing environment, well planning, control and operation require both expert knowledge of the area, and decision support capabilities. This paper discusses the features of decision support systems and expert systems, and their integration to support the major functions from marketing and strategic level considerations to manufacturing operational planning and process. From the hierarchical structure of information flow in a company, this paper attempts to find the best way of combining decision support systems with expert systems in enhancing the planning, control and operational functions in a CIM environment.

\section{REFERENCES}

[1] Chang, C., "Expert Systems for Manufacturing Operations and Management," Proceedings of 1988 North American IBSCUG Conference, Oxford, pp. 220-226, 1988.

[2] Chang, C., "Quality Function Deployment (QFD) Processes in an Integrated Quality Information System," Int. J. of Computers and Industrial Eng., Vol. 17, Nos. 1-4, pp. 311-316, 1989.

[3] Chang, C., "The Structure of Quality Information System in a Computer Integrated Manufacturing Environment," Int. J. of Computers and Industrial Engineering, Vol. 15, Nos. 1-4, pp. 338-343, 1988.

[4] Chang, C. and T. Steiner "Computer Aided Manufacturing Planning and Control Expert Model," 1986 IASTED Applied Simulation and Modeling Conference Proceedings, Vancouver, pp. 536-540. 1986.
[5] Chang, C. and L. Tsui "Integrated Manufacturing Planning \& Control System Using MRP II," Proceedings of the ISMM Int. Symposium of Computer Applications in Design, Simulation and Analysis, Reno, pp. 302-305, 1989.

[6] Chang, C. and K. Yeung "Manufacturing Process Planning Expert Systems," Proceedings of Third Int. Conference of Expert Systems: Theory \& Applications, Los Angeles, pp. 126-129, 1988.

[7] Groover, M. and E. Zimmers, Jr. CAD/CAM: Computer-aided Design and Manufacturing, Prentice Hall, Englewood Clifis, 1984.

[8] Heragu, S. and A. Kusiak "Analysis of Expert Systems in Manufacturing Design," IEEE Transactions on Systems, Man and Cybermetics, Vol. SMC-17, No. 6, pp. 898-912, 1987.

[9] Laudon K. and J. Laudon Management Information Systems, Macmillan Pub., New York, 1988.

[10] Long, L, Management Information Systems, Prentice Hall, Englewood Cliffs, 1989.

[11] Miska, K. "The New Mavens of Manufacturing," Manufacturing Engineering, Oct. pp. 36-39, 1989

[12] Rouse, W. "Intelligent Decision Support for Advanced Manufacturing Systems," Manufacturing Review, Vol. 1, No.4, pp. 236-243, 1988.

[13] Sharit, J., R. Eberts and G. Salvendy "A Proposed Theoretical Framework for Design of Decision Support Systems in Computer-integrated Manufacturing Systems: A Cognitive Engineering Approach," Int. J. of Production Research, Vo. 26, No. 6, pp. 1037-1063, 1988. 